\title{
Competency-Based Training (CBT) Approach to Teaching and Learning in Higher Technical Institutions (HTI) in Ghana
}

\author{
William Gyadu-Asiedu ${ }^{1}$, Smile Dzisi ${ }^{1}$, Patience Kwakyewa Asirifi ${ }^{1}$, Augustine Atta \\ Boamaa $^{2}$
}

${ }^{1}$ Koforidua Technical University, Koforidua, Ghana

2 Sunyani Technical University, Sunyani, Ghana.

\begin{abstract}
Competency-Based Training (CBT) was introduced in the HTIs (i.e. Polytechnics, most of which has become and Technical Universities) in Ghana to provide graduates with appropriate knowledge and skills to efficiently perform work place roles in industry and administration. This is a preliminary study to undertake an appraisal of CBT since its implementation in the HTIs. The study focuses on the mode of delivery of CBT, the modes assessment, the benefits and the challenges. Mixed methods research design was used to collect and analyse data from five Polytechnics using random sampling. A total of 510 respondents comprising lecturers and students who engaged in various CBT programmes participated in the study. The findings reveal that CBT helps trainees to acquire competencies/skills required in the performance of jobs. CBT also encourages the adoption of flexible delivery and learning methods in Polytechnics in Ghana. Among the major challenges facing CBT in the Polytechnics are finance and logistics as well as the "pen-and-paper test". The study recommends that proper identification of trainee skills, adoption of appropriate teaching and assessment methods are used in the delivery of CBT. In addition, adequate funding required for CBT training and equipment is also recommended. Most significantly, stronger collaboration with both public and private sector firms in the industry is needed. Finally, commitment and support from all stakeholders in polytechnic education is necessary for the sustainability of CBT.
\end{abstract}

Keywords: Competency-Based Training; Polytechnic Education; Employable Skills; Job Performance

\section{Introduction}

One prominent challenge confronting Ghana's labour market is the mismatch between the supply of labour and competencies required for effective productivity at work (Boama, 2014). Many authors have attributed this to several reasons, some of which are shortage of the required labour force and the lack of competencies required of graduates from the technical institutions and polytechnics (Afeti et al., 2003; Nsiah-Gyabaah, 2007. The Ghanaian industry's perception about fresh graduates is that, the graduates are not competent enough to fit into the job market straight away. These inadequacies are believed to be as a result of the poor teaching and learning approaches adopted for various programmes in the various training institutions. The phenomenon of unemployed graduates has come to stay. A common reason is that there is a lack of clear-cut, structured and workable hands-on training that will empower polytechnic graduates to be readily employed by industry. This is also blamed on the fact that many courses and methods of teaching and training have left some practical aspects out. There is therefore the need for introduction of Competence Based Training (CBT) in most of the training institutions and polytechnics in Ghana.

According to the World Data on Education, the following mission, vision and legislation establish TVET education in Ghana (UNESCO-IBE (2011):

\subsection{Relevant TVET legislation}

- The Council for Technical and Vocational Education and Training (COTVET) Act 718 of 2006 established the Council to 
coordinate all aspects of Technical and Vocational Education and Training (TVET) in the country, including policy formulation. This includes the formulation of policies for skills development across pre-tertiary, tertiary education (formal, informal and non-formal). The main objectives of the Council, according to Gondwe and Walenkamp (2011), are to address unemployment issues, particularly, to ensure that the youth, are given competitive, employable and entrepreneurial skills within the formal and informal sectors, and that graduates from TVET institutions (formal, informal and non-formal) are endowed with employable and entrepreneurial skills.

- The National Accreditation Board Act 744 of 2007, provides for the establishment of the Board as an entity responsible for the accreditation of public and private tertiarylevel institutions with regard to content and standard of programmes offered.

- The Polytechnic Act 745 of 2007, provides a clear mandate to Polytechnics to be responsible for tertiary education in the fields of manufacturing, commerce, science, technology etc., and to provide opportunities for skills development, applied research and publication of research findings.

According to the World's TVET database on Ghana, by 2011 there were 440 TVET providers, of which 188 were public and 252 private. OECD (2008) outlined that, there were 440 public and 500 private TVET institutions in 2007 (UNESCOUNIVOC, 2012).

Focusing on the formal sector, graduates from Junior High Schools, can choose to continue their studies in any of the following: Senior High Schools (SHS), Secondary Technical Schools or Technical Institutes. Progression of successful graduates in their pursuit of formal education is then made possible to the tertiary level. COTVET provides a framework for certification of TVET programme which enables one to progress from basic apprenticeship level to doctorate level through nine (9) well delineated levels. These levels compare with the existing formal education levels (Table 1).

\section{Table 1}

COTVET Framework for certification (NTVETQF) Levels

\begin{tabular}{lll}
\hline Levels & Recommended Qualification Band & Equivalent Academic Qualifications \\
\hline 9 & $\begin{array}{l}\text { Doctorate degree } \\
\text { (Professional/Techno-logy) }\end{array}$ & Doctorate Degree \\
8 & $\begin{array}{l}\text { Master's degree } \\
\text { (Professional/Technology) }\end{array}$ & Master's degree \\
7 & $\begin{array}{l}\text { Bachelor's degree } \\
\text { (Professional/Techno-logy) }\end{array}$ & Bachelor's degree \\
6 & Higher Diploma & No Equivalence \\
5 & Diploma & Diploma \\
4 & Certificate II & West African Senior School \\
3 & Certificate I & Certificate Examination \\
2 & Proficiency II & No Equivalence \\
1 & Proficiency I & Basic Education Certificate \\
\hline
\end{tabular}

Obtained from COTVET website as obtained from UNESCO-UNEVOC (2012).

TVET as a concept is, thus, expected to provide trainees with the needed skills required by industries level by level. However, this has not received the needed attention as compared with other formal education curricula (Nsiah-Gyabaah, 2007). Yet, all around in the world, it is indisputable that countries have advanced on the wheels of technology, i.e.
TVET. In Ghana, local artisans and entrepreneurs who highly patronize the informal training sector play a vital role in the national economy by promoting technical and vocational skills through traditional apprenticeship training scheme (Amegashie-Viglo, 2005). However, it has been observed that not enough efforts have been made by 
both the private and public sectors (government) to contribute towards the development of TVET despite the significant role it has played so far in addressing unemployment problems, and an even bigger role it can potentially play towards national development (Boama, 2014; Nsiah-Gyabaah, 2007; Owusu \& Nisah, 2009). Thus, the commitment of the key stakeholders of TVET education in Ghana has been found to be woefully disappointing: governments, technocrats and the general public, especially when it comes to funding (Owusu \& Nisah, 2009).

\subsection{Delivering TVET in higher technical education through $C B T$}

CBT was introduced into the HTIs in Ghana to help develop competent individual with transferable skills, link education and training in skills needed by the employer among others (COTVET, 2009). By the year 2000, succeeding governments had ensured that each of the ten (10) regions in the country has one HTI in order to ensure the nationwide implementation of TVET education at a higher level.

\subsection{Objectives of tertiary technical education}

The Polytechnic Law (PNDCL 321 of 1992) was replaced by the Polytechnics Law (Act 745) in 2007 and now Technical University Act, 2016 (Act 922), which "provides for the establishment of Technical Universities; to provide for the conversion of polytechnics to Technical Universities and to provide for related matters". This gives a clear mandate to the Polytechnics in Ghana. The aims and objectives of the Polytechnics as stated in the Polytechnics Law (Act 745) is as follows:

a) "Provide tertiary education in the fields of manufacturing, commerce, science, technology, applied social sciences and applied arts, etc.

b) Provide opportunities for skills development, applied research and publication of research findings.

c) Encourage study in technical subjects at tertiary level".

For the latter, the aims of Technical University "are to provide higher education in engineering, science and technology based disciplines, technical and vocational education and training, applied arts and related disciplines as the Council of the Technical University may, in consultation with the National Council for Tertiary Education determine...."
A deeper analysis of the two Acts shows that there is, essentially, no difference between the two when it comes to the emphasis of TVET. However, the implementation of the CBT model of teaching and training in the TVET sector has been a difficult one. It has involved changes in the relationship between TVET and industry, particularly in the introduction of industry competency standards as the basis for TVET curriculum, curriculum development, and its delivery and assessment. Findings from previous studies have revealed that despite the introduction of CBT in the country about a decade ago, it is still struggling to be fully implemented at the higher technical education level. The sad results is that the country is far from achieving its goals from TVET education: graduate unemployment situation in Ghana still remains high and it is as a result of THE continuous lack of practical skills among graduates, especially among polytechnic graduates (Boama, 2014; Nsiah-Gyabaah, 2007; COTVET, 2009). This is therefore a preliminary study to assess the adoption of the CBT approach by Polytechnics. The specific objectives of the study are in three-fold: to assess CBT mode of delivery and evaluations, to ascertain the benefits Polytechnics have derived from the adoption of CBT, and to identify the challenges encountered.

\subsection{Conceptualizing competency-based education}

According to Smith et al. (1997), CBT is defined as a form of education where the focus of training is the outcome of the training, the outcome is measured against specific standards, not against other students; and the standards relate to industry. Watson (1990) concluded that competency-based instruction has tremendous potential for training in the industry. According to Waymark (1997), CBT has had a major impact on the evolution of Vocational Education and Training (VET). This concept is depicted in Figure 1: 


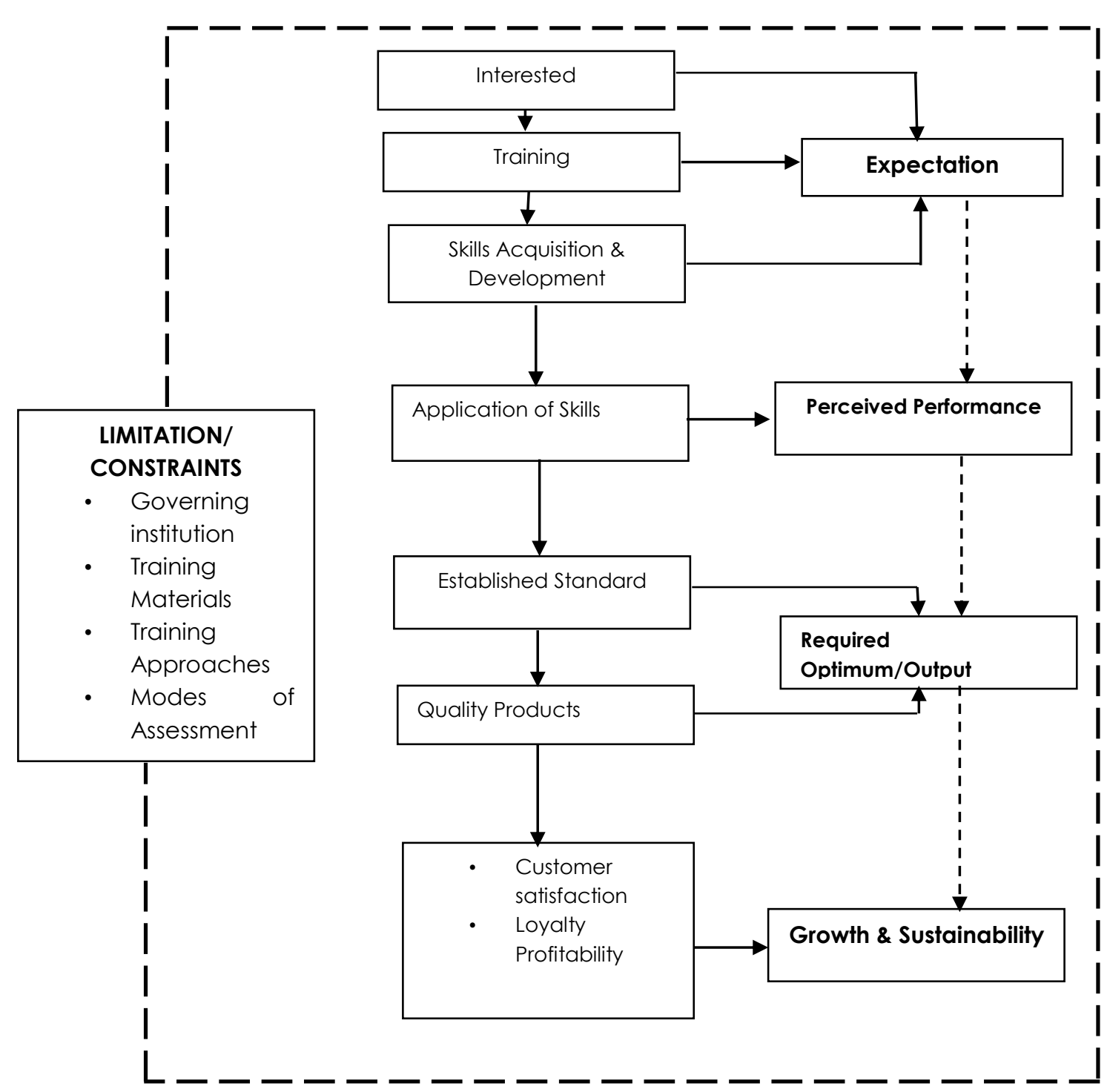

Fig. 1: Conceptual framework for CBT Education

From the diagram above, it could be observed that CBT is a structured approach to training and assessment that is directed toward achieving specific outcomes. It is about assisting individuals to acquire skills and knowledge so they are able to perform a task to a specified standard under certain conditions (COTVET, 2009). In CBT, the outcomes to be achieved are clearly stated so that learners know exactly what they have to be able to do, trainers know what training or learning is to be provided and organizations know the skill levels required of their people (employees). The emphasis on competency-based training is on "performing" rather than just "knowing". It could then be observed from the figure 1 above that some key variables are embedded in this concept of CBT, which are an "expectation" of skill levels, desired or "perceived performance" from trainees and "required output" to result in "growth and sustainability" of industry amidst some constraints. These are explained in the ensuing.

\subsubsection{Expectation}

There is an expected level of competence required of trainees and employees. Competency could be defined in terms of what a person is required to do (performance), under what conditions it is to be done (conditions) and how well it is to be done (standards) (Harris et al., 1995). Harris et al. (1995) stated that in a CBT system, the unit 
of progression is mastery of specific knowledge and skills and is learner-centred. Two key terms used in competency-based training are Skill and Competency.

Competency-based education is, thus, perceived by some as the answer, by others as the wrong answer, to the improvement of education and training in the complex contemporary world (Harris et al., 1995). Some critics argue that, the approach is conceptually confused, empirically flawed, and inadequate for the needs of a learning society (Chappell 1996; Ecclestone, 1997; Hyland, 1994).

Competency-based training is an avenue to achieve a highly knowledgeable and skilled workforce. A systematic approach to training that is monitored and revised in the light of performance and outcome is the hallmark of a competency-based training programme. Clear and detailed outcomes or competency statements are used to develop the training curriculum and measure learners' competence. Competency statements are derived from a thorough job analysis of the learner's duties, which contribute to the training goal of meeting individual learners' needs as they master various skill levels (COTVET, 2009).

Waymark (1997) pointed out that CBT has had a major impact on the evolution of Vocational Education and Training (VET). Decisions concerning methods of delivery, teaching and learning, assessment, and transferability of qualifications have been strongly influenced by a competency-based training environment (Lowrie et al., 1999). In Australia, CBT has been legislated to a greater extent than most other countries. Policy directives at the national level in the early 1990's have ensured that competency-based training would become the preferred method of delivery of Vocational Education and Training (VET) in Australia, with substantial implementation occurring by 1993 (Lowrie et al., 1999).

The objectives of a competency-based training in the HTIs, as outlined in COTVET (2009) are to: select clear and measurable standards, develop competent individuals with transferable skills that will link education and training in skills needed by employers while providing objective quality assured system which will have the confidence of all users, i.e., learners educational establishments and employers. Others include the development of an individual's full potential based on interest to promote the concept of lifelong learning.

According to Foyster (1990), Delker (1990) and Norton (1987), there are a number of characteristics of competency-based programs. The key ones are carefully selected competencies to be learned, integration of supporting theory with skill practice, supporting of performance of skills through acquired knowledge; detailed training materials keyed to the competencies to be achieved and are designed to support the acquisition of knowledge and skills; methods of instruction involve mastery learning Other essential components include participants' knowledge and skills assessment at entry, self-paced learning; flexible training approaches including large group methods, small group activities and individual study are essential components. Also, a variety of support materials including print, audiovisual and simulations (models) keyed to the skills being mastered are used; their assessments relate to the standards and are normally done on a continuous basis. CBT involves of a wide range of stakeholders, namely education and training practitioners, business leaders and industry in determining the required standards, as satisfactory completion of training is based on achievement of all specified competencies.

One of the primary advantages of CBT is that the focus is on the success of each participant. Watson (1990) states that, the competency-based approach "appears especially useful in training situations where trainees have to attain a small number of specific and job-related competencies". Norton (1987) identified the benefits that can be obtained from adopting the CBT approach. According to him CBT increases motivation amongst learners; it encourages flexible delivery and learning; it focuses on skill, knowledge and attitude and it produces competent graduates with transferable skills.

Norton (1987) further stated that CBT encourages team work. It enables participants to achieve and acquire competencies required in the performance of their jobs. Participants build confidence as they succeed in mastering specific competencies. Participants receive a transcript or list of competencies they have achieved. Also, training time is used more efficiently and effectively as the trainer is a facilitator of learning as opposed to a provider of information. More training time is devoted to working with participants individually or in small groups as opposed to presenting lectures and, more training time is devoted to evaluating each participant's ability to perform essential job skills.

For trainees, CBT allows them to accept responsibility for their own learning (Watson 1999; Foyster, 1990). A CBT programme can reduce the 
time of training for some trainees. Self-paced learning gives trainees time to master a competency before proceeding to the next and takes into account the needs of individual trainees. The CBT programme improves trainees' chances of doing well in a course. Trainees are better motivated and more focused on learning. Career paths are more related to skills and multi-skill development.

\subsubsection{Perceived performance}

Having acquired the expected skills and competencies, it is of the essence that the desired performance would be achieved in the field of work. According to Chappel et al. (1996), the skill is a task or group of tasks performed to a specific level of competency or proficiency which often use motor functions and typically, require the manipulation of instruments and equipment (Some skills, however, such as counselling, are knowledge and attitudebased). Competency is a skill performed to a specific standard under specific conditions. Competency comprises the specification of knowledge and skill and the application of that knowledge and skill within an occupational industry level of the standard of performance required in employment (Chappel et al., 1996) as evident in diagram 1 above.

Proponents of competency based-training promote it as a way to improve the correspondence between education/training and workplace requirements (Harris et al., 1995). It is individualized, emphasizes outcomes (what individuals know and can do), and allows flexible pathways for achieving the outcomes. It makes as clear as possible what is to be achieved and the standards for measuring achievement. In theory, it overcomes the divide between hands and mind, theory and practice, general and vocational education.

Specific advantages for employers include the fact that CBT programmes can make training more flexible and improve productivity; employees can be trained in the competencies needed for their jobs without having to complete the entire course and CBT certifies that each competence of an employee has been assessed to the standards needed in the workplace (Delkar, 1990).

Furthermore, what employees already know and can do can be recognized in the CBT to give the programme their credit for previously acquired knowledge and skills relevant to their job. Due to this, some trainees will become competent in a shorter time and there will be a lower cost to the employer for their training. Employees can be involved in the development, presentation and assessment processes of training which help in the effective application of skills gained to the benefit of the organisation.

Essentially, CB'T makes assessing a simpler process as it requires that trainees achieve stated training outcomes by reaching or bettering the specified standards (Harris et al., 1999). Various delivery methods can be used, such as self-paced learning. Lecturers and learners can be more confident about whether or not a trainee can do a job because trainees are assessed individually. Evidence of competence allows trainees to move between industry, training programme and the institutions more effective. The competencies needed for the job can be aligned with training outcomes and the ability to exhibit competence on the job.

These acquired competencies are then channeled through the appropriate process amidst established standards or rules to achieve the employers' aim of optimum output.

\subsubsection{Required output, growth and sustainability}

Figure 1 explains that proper application of skills and competencies acquired through CBT results in the production quality output, which would meet customer needs to result in satisfaction and loyalty. Less waste is an experience which will reduce cost of production to result in increased profitability of the employer or industry.

According to Thomas and Potter (1992), a nation can only develop or improve through the level of its gross national product (GNP). Hence, developing the capacities of employees or human capital to enable them produce at a higher level of competence is key. The return on investment for society will be a skilled workforce that will enable global competitiveness and economic growth, while the return of the individual will be a better career path, increased earning and a better quality of life.

\subsubsection{Limitations}

As indicated in the conceptual framework above, the implementation of the CBT model of teaching and training in the TVET sector has been a difficult one. It has involved changes in the relationship between TVET and industry, particularly in the introduction of industry competency standards as the basis for 
TVET curriculum, in the way the curriculum is developed, in its delivery and assessment.

Afeti et al. (2003) has observed that the changes introduced into the technical institutions during the 1990s, by the adoption of CBT, have impacted upon everyone working in the vocational education and training (VET) sector. It can be argued, however, that the greatest effects have been upon TVET teachers and trainers, since they have had to change their everyday practice to accommodate CBT. Moreover, they hold the ultimate responsibility for ensuring that CBT makes a difference to TVET outcomes.

According to Harris et al (1999), prior to implementing CBT, it is important to consider limitations: Unless initial training and follow-up assistance is provided to the trainers, there is a tendency to "teach as we were taught" and CBT trainers quickly slip back into the role of the traditional teacher. A CBT course is only as effective as the process used to identify the competencies. When little or no attention is given to identification of the essential job skills, then the resulting training course is likely to be ineffective.

Another limitation as indicated above is the materials or approaches adopted in the process. Chappel (1996) argued that a course may be classified as competency-based, but unless specific CBT materials and training approaches (e.g. Teaching guides, checklists and coaching) are designed to be used as part of a CBT approach, it is unlikely that the resulting course will be truly competency-based. Watson (1999) and Delker (1990) added that CBT involves a lot of administrative work. CBT provides less flexibility in meeting defined standards. It is expensive to implement and it is time consuming.

Relating to the mode of assessment, assessment of competence is not a set of exams; it is the basis for the certification of competence, and is carried out as a process to gather pieces of evidence concerning the performance and knowledge of an individual in relation to a competent standard (Harris et al 1999). This becomes an appreciable role as an instrument of diagnosis, both for the worker and the employer. It therefore measures whether a learner is competent or not competent (Watson, 1990; Hendricson and Kleffner, 1998). Only two possible outcomes can be the result of the standard process, that is, they are competent (they can perform what is stated in the standard) or they are not yet competent (they cannot yet perform what is stated in the standard). Hendricson and Kleffner (1998) explained further that competency-based assessment is not designed to measure a learner who is $30 \%$ or $50 \%$ or $80 \%$ etc., "competent". Norm Reference Assessment on the other hand is an assessment that measures how learners compare with each other (Hendricson and Kleffner, 1998; Watson, 1990). The results of the test are given as percentages $(50 \%, 80 \%$ and $90 \%)$ or sometimes these are translated into a range (pass, merit and distinction). Below is a table depicting the difference between the traditional and the CBT modes of assessment.

Table 2

Differences between traditional assessment and the CBT

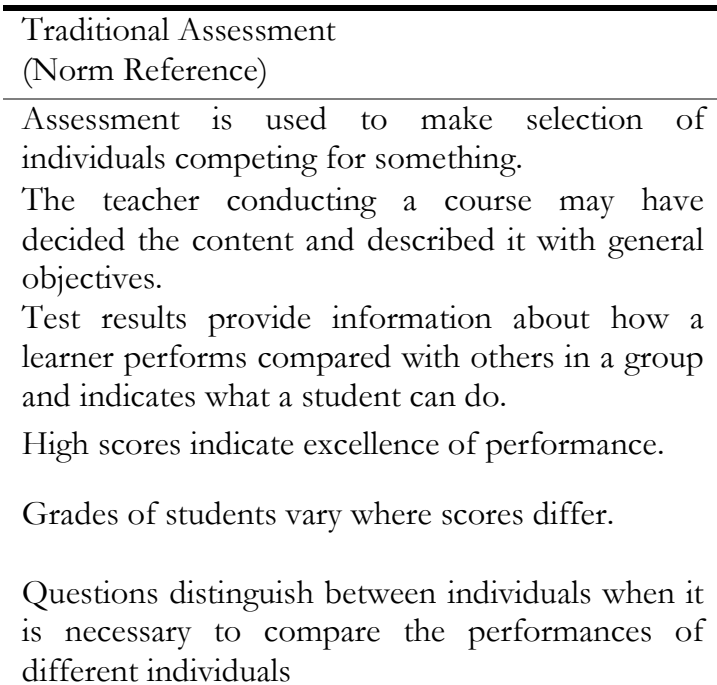

different individuals
Competency-Based Assessment

(Criteria Referenced)

Tests are stopping point to determine if a student has gained the knowledge and/or the skills to proceed to the next stage.

Course content is defined by specific objectives and standards.

Scores give an accurate indication of what a student can do and cannot do.

Identification of excellent performance often not appropriate.

Grades are not necessary as achievement of standards is the goal.

Questions must match the objectives and are required to obtain information about what a student can do and cannot do. 
In a traditional educational system, the unit of progression is time and it is teacher-centred. There appears to be substantial support for competencybased training. Norton (1987) believes that competency-based training should be used as opposed to the "medieval concept of time-based learning." Foyster (1990) argues that using the traditional "school" model for training is inefficient. After in-depth examinations of three competencybased programmes, Watson (1990) concluded that competency-based instruction has tremendous potential for training in the industry and that successful training programmes were competencybased.

In general terms, however, CBT can be explained as having a focus on the outcome of training (ANTA, 1997). These outcomes are measured against specific standards and not against other students and the standards are directly related to the industry. It is reasonable to assume that competency-based training approaches have affected individuals in different ways considering the diverse nature of the sector.

\section{Methodology}

This study focuses on the assessment of the CBT approach to Polytechnic education in Ghana. The study employed a mixed methodology research design where both qualitative and quantitative methods were used. Ten (10) HTIs in Ghana appropriately constituted the study population with the members of the polytechnics: staff and students who engaged in various CBT programmes constituting the target population. Five of these in: Koforidua, Ho, Sunyani, Accra and Tamale were randomly selected to form the sample frame for the study.

The data obtained from the five polytechnics revealed that a total number of 1076 students were offered a CBT course across all disciplines in the polytechnics. This is quite a small number since nonof the five HTIs have less than 3000 students. The simple random sampling method was used to select a total of 600 students across all programmes in the five polytechnics. Table 3 presents information on the breakdown of the population, sample size and response rate per each of the polytechnics. Based on the sample of the study, the appropriate primary and secondary data were collected, presented using tables and subsequently analysed. The secondary data comprised documentary information obtained from the HTIs regarding the CBT programmes, implementation, curriculum, assessment criteria and challenges, mode of delivery and learning among others.

\section{Table 3}

Population, Sample Size and Response Rate

\begin{tabular}{lllll}
\hline Polytechnics & $\begin{array}{l}\text { No. of Students } \\
\text { engaged in CBT } \\
\text { Programmes }\end{array}$ & Number Selected randomly & Responses & Percentage (\%) \\
\hline Koforidua & 146 & 100 & 96 & $96 \%$ \\
Ho & 280 & 150 & 135 & 90 \\
Sunyani & 110 & 100 & 85 & 85 \\
Accra & 370 & 150 & 120 & 80 \\
Tamale & 170 & 100 & 74 & 74 \\
Total & 1076 & 600 & 510 & 85 \\
\hline
\end{tabular}

A well-structured questionnaire was administered to six hundred (600) students from the five polytechnics through field survey. Stratified sampling was used to select a proportional representation of CBT students out of the six hundred (600) students from each of the HTIs across the various academic programmes of study, namely: Engineering, Building Technology, Fashion and Estate Management. In addition, fifteen (15) out of the twenty-five (25) tutors involved in CBT programmes were purposefully selected and an 
in-depth interview was conducted with them, three from each of the five institutions.

Critical issues pertaining to what is taught, how it is taught, what benefits are derived from the CBT approach and what challenges are encountered in the adoption of the CBT approach, were measured by using five items on a 6point Likert scale in the questionnaire survey asking the respondents to rate the applicable items accordingly. Also, open-ended questions were asked; and all these questions were further explored during the interviews with the tutors.

Data were collected in all the five institutions, from January to August 2014. A total of 510 usable questionnaires was collected out of the 600 that were distributed, yielding 85 percent response rate. The quantitative data were analysed using SPSS to derive the descriptive statistics and the qualitative data was analysed manually using content analysis.

\section{Results and Discussions}

\subsection{Socioeconomic and demographic status of respondents}

In an attempt to ascertain information on the background of staff and students engaged in CBT, questions were asked about their age, sex, educational background and the programme of study. The results on the demographic characteristics of the respondents are presented in Table 4 . In terms of age distribution, it can be seen that the majority $(60 \%)$ of the respondents fall within the age brackets of 18-25 while 32 percent of them fall within the age bracket of 26-35 years. 6 percent and 10 percent fall within the ages of 36-50 and 51-60 respectively. This implies that majority of the stakeholders of CBT are youthful and fall within the constitutional working age brackets of 18-60. By extention, CBT cuts across all ages and does not depend on differences in age groups.

The information on the gender of respondents as presented in Table 4 indicates that males : females ratio is $6.7: 1$ Furthermore, table 5.0 revealed that the majority $(68 \%)$ of the respondents have received secondary education and 10 percent had diploma qualifications. On religious affiliation, 67 percent of the respondents are Christians, 30 percent are Moslems, while 3 percent practice other religions. On respondents' departments, 51 percent of the respondents are in Building Technology, 28 percent is in Automotive Engineering, 10 percent are in the
Fashion department and the remaining 6 percent and 5 percent are in Civil Engineering, and Estate Management Departments respectively. This means that majority of respondents who are students, lecturers and heads of department of the selected polytechnics are in the Building Technology departments of the various polytechnics.

\subsection{CBT mode of delivery and assessment in the polytechnics}

Findings regarding respondents' general perspective on CBT mode of delivery and assessment in the Polytechnics were obtained. The results show that the majority of respondents $(65 \%)$ indicated that the major form or mode of delivery and assessment of CBT is the normal or traditional assessment popularly called the "pen-on-paper" test. Some of the respondents (25\%) indicated that continuous/integrative assessment was done while the remaining respondents $(15 \%)$ argued that workplace assessment/industrial attachment assessment was used. This implies that the major form of CBT assessment and mode of delivery in the Polytechnic is more of the traditional or normative reference assessment.

Again, respondents were asked if CBT test scores give an accurate indication of a student's competency. The results show that the majority of respondents $(65 \%)$ answered in the negative. This indicates that CBT test scores do not give an accurate indication of a student's competency. The results also imply that the usual assessment method of traditional (pen-on-paper test) does not help to give an accurate picture of the impact of CBT on students' competence. However, a good percentage of the respondents (58\%) said that during the CBT mode of delivery and assessment, trainees' competencies are measured with specific standards. 
Table 4a

Demographic and Socio-Economic Status of Respondent

\begin{tabular}{|c|c|c|c|}
\hline Item & Characteristics & Freq & $\%$ \\
\hline \multirow[t]{5}{*}{ Age } & $18-25$ & 308 & 60.4 \\
\hline & $26-35$ & 162 & 31.7 \\
\hline & $36-50$ & 30 & 5.9 \\
\hline & $51-60$ & 10 & 9.61 \\
\hline & Above 60 & 0 & 0.0 \\
\hline Total & & 510 & 100.0 \\
\hline \multirow[t]{2}{*}{ Gender } & Male & 445 & 87.3 \\
\hline & Female & 65 & 12.7 \\
\hline Total & & 510 & 100.0 \\
\hline \multirow[t]{4}{*}{ Educational Level } & Secondary & 345 & 67.6 \\
\hline & Diploma & 50 & 10 \\
\hline & Undergraduate & 100 & 19.5 \\
\hline & $\begin{array}{c}\text { Masters } \\
\mathrm{PhD}\end{array}$ & $\begin{array}{c}11 \\
4\end{array}$ & $\begin{array}{l}2.1 \\
0.8\end{array}$ \\
\hline \multirow[t]{5}{*}{ Total } & & 510 & 100.0 \\
\hline & Academic Department & & \\
\hline & Building Technology & 259 & 50.7 \\
\hline & Estate Management & 25 & 4.9 \\
\hline & $\begin{array}{c}\text { Civil Engineering } \\
\text { Automotive Engineering } \\
\text { Fashion }\end{array}$ & $\begin{array}{c}30 \\
146 \\
50\end{array}$ & $\begin{array}{c}5.9 \\
28.6 \\
9.9\end{array}$ \\
\hline Total & & 510 & 100.0 \\
\hline \multirow[t]{4}{*}{ Religion } & Islam & 154 & 30.2 \\
\hline & Christianity & 342 & 67.1 \\
\hline & Traditional & 0 & 0.0 \\
\hline & Other & 14 & 2.7 \\
\hline Total & & 510 & 100.0 \\
\hline Total & Total & 510 & 100.0 \\
\hline
\end{tabular}

\subsection{CBT mode of delivery and assessment in the polytechnics}

Findings regarding respondents' general perspective on CBT mode of delivery and assessment in the Polytechnics were obtained. The results show that the majority of respondents $(65 \%)$ indicated that the major form or mode of delivery and assessment of CBT is the normal or traditional assessment popularly called the "pen-on-paper" test. Some of the respondents (25\%) indicated that continuous/integrative assessment was done while the remaining respondents $(15 \%)$ argued that workplace assessment/industrial attachment assessment was used. This implies that the major form of CBT assessment and mode of delivery in the Polytechnic is more of the traditional or normative reference assessment.

Again, respondents were asked if CBT test scores give an accurate indication of a student's competency. The results show that the majority of respondents $(65 \%)$ answered in the negative. This indicates that CBT test scores do not give an accurate indication of a student's competency. The results also 
imply that the usual assessment method of traditional (pen-on-paper test) does not help to give an accurate picture of the impact of CBT on students' competence. However, a good percentage of the respondents $(58 \%)$ said that during the CBT mode of delivery and assessment, trainees' competencies are measured with specific standards.

The results of CBT tests and grades being used as determinants of students' knowledge and skills for progression also shows that the majority $(63 \%)$ of respondents agrees that tests and grades are stopping points in determining if a student has gained the required skills to progress onto the next level of their CBT. This emphasizes that in spite of the practical skills, CBT offers to trainees, test and grades are still used to determine if a student has gained knowledge and/or skills before he/she can proceed to the next stage of their CBT programme.

Information was elicited from respondents on whether CBT mode of assessing performance takes place in workplace settings or simulated workplace setting. The results indicate that assessment of performance of the CBT students does not take place in a workplace setting or a stimulated workplace setting. The majority of respondents $(82 \%)$ were of the view that appropriate settings were not provided for CBT. This result brings to light some of the limitations indicated in the conceptual framework explained above.

\subsection{The benefits of competency-based training to polytechnic education}

Based on the review of literature, five (5) main benefits have been identified and adopted as a benchmark for measuring the benefits obtained from CBT. These benefits have been discussed with respect to the various perspectives of the respondents (heads of polytechnics, lecturers and students). These benefits are: motivating learners, encouraging flexible delivery and learning methods, producing competent graduates with transferable skills, acquisition of competencies/skills required in the performance of jobs, and building confidence and encouraging teamwork.

The findings presented in Table 5 reveal that out of the 510 respondents, $21 \%$ percent of them strongly agree that CBT motivates learners. The findings from the interviews also emphasized the results that CBT helps in improving the trainee's chance of doing well academically in a course as opposed to traditional "sole classroom" educational system where the unit of progression is time and it is teacher-centred instead of being student-centred. Additionally, the respondents argued out strongly that CBT motivates and makes them more focused on learning. This means that the mode of delivery and training programmes of CBT motivates students to be more focused on learning than the traditional learning methods. Impliedly, those who are engaged in CBT in the Polytechnics believed that the style, form of education and training of CBT have a great tendency of motivating students to develop interest in technical and vocational education. This finding is thus consistent with the findings of Norton (1987) which emphasized that CBT increase motivation among learners. Significantly, this satisfies a major objective of the Polytechnic Law (PNDCL 321 of 1992) (Act 745) which is geared towards encouraging the study of technical subjects at the tertiary level.

It was also found that CBT encourages the adoption of flexible delivery and learning methods. As shown in Table 5, the majority of respondents $(20 \%)$ indicated that the mode of delivery and learning of CBT is flexible for students. This affirms earlier works by Norton (1987) who asserts that CBT encourages flexible delivery and learning. Moreover, Lowrie et al (1999) also supports this finding that CBT is perceived to be the panacea to the improvement of education and training for the growing complex contemporary world where technology has made learning so flexible. 
Table 5a

The benefits from Competency-based Training to Polytechnic Education

\begin{tabular}{lll}
\hline Benefits & Frequency & Percentage \\
\hline $\begin{array}{l}\text { Motivation for } \\
\text { Learners }\end{array}$ & 112 & 21.96 \\
Encouragement of Flexible Delivery and Learning & 102 & 20.00 \\
Competent Graduates with transferable skills & 97 & 19.02 \\
Acquisition of required job Competencies/skills & 117 & 22.94 \\
Confidence Building and Teamwork & 82 & 16.08 \\
Total & 510 & 100.00 \\
\hline
\end{tabular}

Table 5b

The benefits from Competency-based Training to Polytechnic Education

\begin{tabular}{|c|c|c|}
\hline Benefits of CBT & $\begin{array}{l}\text { Weighted } \\
\text { Mean }\end{array}$ & Ranking \\
\hline Motivation of Learners & 3.81 & 2 \\
\hline $\begin{array}{l}\text { Encourage Flexible learning } \\
\text { method }\end{array}$ & 3.85 & 1 \\
\hline $\begin{array}{l}\text { Achieving Competent skill } \\
\text { required for performance }\end{array}$ & 3.77 & 3 \\
\hline $\begin{array}{l}\text { Improve Trainees chance of } \\
\text { Doing well on Job }\end{array}$ & 3.40 & 9 \\
\hline $\begin{array}{l}\text { Confidence in encouraging } \\
\text { team work }\end{array}$ & 3.70 & 4 \\
\hline $\begin{array}{l}\text { Accepts responsibility for self- } \\
\text { learning }\end{array}$ & 3.39 & 10 \\
\hline $\begin{array}{l}\text { Gives the trainee time to master } \\
\text { competency before next level }\end{array}$ & 5.58 & 8 \\
\hline $\begin{array}{l}\text { Expects that the trainee gets } \\
\text { competence for job } \\
\text { requirements }\end{array}$ & 3.67 & 5 \\
\hline $\begin{array}{l}\text { Trainees are better motivated } \\
\text { and more focused on learning }\end{array}$ & 3.64 & 6 \\
\hline $\begin{array}{l}\text { Aligning competence with } \\
\text { training outcome }\end{array}$ & 3.51 & 7 \\
\hline $\begin{array}{l}\text { A trainee's competencies goes } \\
\text { with specific standard }\end{array}$ & 3.15 & 11 \\
\hline $\begin{array}{l}\text { Assessment of performance } \\
\text { takes place in a workplace } \\
\text { setting }\end{array}$ & 1.97 & 12 \\
\hline
\end{tabular}

The results from the study were in agreement with the earlier findings that CBT helps to produce competent graduates with transferable skills. The results presented in Table 5 indicate that 19.02 percent of the respondents agreed that CBT helps give trainees'/students' time to master a particular competency before proceeding to the next level.
Again, it was revealed from the interviews conducted that CBT helps trainees to attain a small number of specific and job-related competencies. The above revelation agrees with Watson's (1990) findings. It was also found that competencies of those engaged in CBT align with the objectives and outcomes of CBT. This also shows that CBT help to improve the 
correspondence between education/training and workplace requirements as posited by Harris et al. (1995).

As indicated in table $5 \mathrm{a}$, the majority of the respondents $(22 \%)$ answered that CBT helps students to achieve competencies/skills required in the performance of their job. This implies that the objective of CBT to help students achieve required competencies needed for developing industries is achieved. This indicates also, that the implementation of CBT in the selected polytechnics is living up to its objectives of inculcating career-oriented habits in students. This is in line with the argument of Foyster (1990), Delker (1990), and Watson (1990) who state that the use of traditional "school" model for training is inefficient and that competency-based instruction has tremendous potential for training and achieving a highly knowledgeable and skilled workforce for industries.

On the question of the benefits of CBT in building confidence and encouraging teamwork among students, 16.08 percent of the respondents said that CBT instills confidence in them and helps them work better in teams. The implication of the above results is that the nature, mode of delivery and learning, assessment and other activities of CBT play significant roles in giving confidence and encouraging teamwork among students. This confirms the position of Norton (1987). With $65 \%$ of the respondents indicating that the major form or mode of delivery and assessment of CBT is the normal or traditional assessment popularly called the "pen-onpaper" test, it follows largely, that the position of Norton (1987) relates very well with the traditional system being practiced in the country's TVET institutions. It also adds credence to the fact that it is a good practice to progressively grow CBT implementation of the traditional system until it is perfected. A follow-up question on the same issues (with additions) showed that the three most important benefits of CBT is that "it encourages flexible learning, motivation of learners and helping to achieve competent skills required for performance". The last three are: "Accepts responsibility for self-learning, A trainee's competencies goes with specifics and Assessment of performance takes place in workplace setting".

\subsection{Challenges facing CBT delivery in the HTIS}

The findings in relation to the challenges facing CBT in the HTIs in Ghana indicate that the majority $(29.02 \%)$ of respondents agree that financial challenges are the major constraints to effective delivery of CBT as presented in Table 6. This implies that Ghana's CBT system is constrained by a lack of financial support which makes it ineffective in the delivery of competent graduates. This underscores the evidence of Fletcher (1998) who asserts that financial challenges constrain the proper implementation of assessment of CBT.

It was realized from the study that logistical constraint is another major challenge facing effective delivery of CBT in Ghana. As presented in Table 6a, large percentages $(26.28 \%)$ of the respondents were emphatic that logistical challenges are major constraints. This implies that lack of or inadequate logistics are a challenge to CBT delivery. This affirms Delker's (1990) assertion that the best approach for CBT training should involve learner-centred instruction using print, instructional technology and simulations which are lacking in many CBT programmes among the HTIs and other TVET institutions in Ghana.

\section{Table 6a}

Challenges facing CBT Effective Delivery in the Polytechnics

\begin{tabular}{lll}
\hline $\begin{array}{l}\text { Challenges } \\
\text { facing CBT } \\
\text { Delivery }\end{array}$ & Frequency & Percentage \\
\hline $\begin{array}{l}\text { Financial } \\
\text { Challenges }\end{array}$ & 148 & 29.02 \\
$\begin{array}{l}\text { Logistical } \\
\text { challenges }\end{array}$ & 134 & 26.28 \\
$\begin{array}{l}\text { Time } \\
\text { Implications }\end{array}$ & 119 & 23.33 \\
$\begin{array}{l}\text { Challenges } \\
\text { Improper } \\
\text { implementation } \\
\text { of CBT } \\
\text { Assessment }\end{array}$ & 109 & 21.37 \\
Method & & \\
\begin{tabular}{l} 
Total \\
\hline
\end{tabular} & 510 & 100.0 \\
\hline
\end{tabular}

Another challenge identified from the study is time implication. Time implication means the period required for students to go through a course to successfully acquire a specific competence. According to table $6 \mathrm{a}$, it can be seen that a large percentage $(23.33 \%)$ of the respondents indicated that the time period required to attain a given competence is very short. This shows that limited time period is allocated 
for CBT in the HTIs. This does not give students enough time to master a specific competence or skill rather they are rushed through a course like the traditional normative educational system. The implication of the above results means, rather frighteningly, that students will not acquire the required skills needed for performing specific jobs in the industry.

Improper implementation of CBT Assessment Methods is another challenge identified in the study. As indicated in table 6a, less than a third of the respondents $(21.37 \%)$ said that improper implementation of CBT assessment method is one of the key challenges facing CBT in Ghana. This result implies that there is an improper implementation of CBT assessment methods in the selected HTIs.

A follow-up test (Table 6b) shows that the most difficult challenge facing CBT is that of "Finance". This followed by "Logistical, Time Implication and finally, Improper Implementation of CBT Assessment Methods". The findings from the study indicate that that CBT test scores do not give an accurate indication of student competency. This implies that the traditional (pen-on-paper test) assessment method being used in assessing practical work in CBT does not help to give an accurate picture on the impact of CBT on students' competence.

\section{Table 6b}

Challenges facing CBT

\begin{tabular}{lll}
\hline Challenges & $\begin{array}{l}\text { Weighted } \\
\text { Mean }\end{array}$ & Rank \\
\hline Financial & 3.74 & 1 \\
Logistical & 3.55 & 2 \\
Time Implication & 3.55 & 3 \\
Improper & 3.49 & 4 \\
Implementation & & \\
of CBT & & \\
Assessment & & \\
Methods & & \\
\hline
\end{tabular}

This emphasizes the argument of Thomson (1991) that, the decision to recognize a performance as satisfactory and to determine competence should be the basis for success of a competency-based program and not the traditional knowledge-based tests used in other educational programmes. Therefore more emphasis should be focused on practical skills and performance of students' competencies other than just raw knowledge.

Also, the mode of delivery and methods of assessment of CBT has major effects on students' competencies. It was found that the place of assessment of CBT has major effects on students' performance due to the fact that CBT institutions with the required facilities are able to impart competent skills and knowledge to its trainees better than CBT institutions without appropriate training and learning facilities. This can have a strong negative influence on trainee's competencies against specific standards set by the COTVET or National Vocational Technical Institution (NVTI) which provides TVET at lower levels in the informal sector. For this reason, Delker (1990) in a study of Business and Industry, found that the best approach for training involved learner-centred instruction using print, instructional technology and simulations. The study uncovered critical information on the benefits of CBT to polytechnic education. CBT helps motivate trainees, encourage flexible delivery and learning methods and help in producing competent graduates with transferable skills. CBT helps students to accept responsibility for their own learning outcomes and also helps students to achieve competencies required for job performance. It can thus be logically deduced from the aforementioned that CBT will help graduates after their acquisition of competent skills and knowledge to create employable jobs that can have the potential to absorb many people who are unemployed. This can help to reduce graduate unemployment among many of the nation's youth. This confirms many similar studies that focus on the benefits of CBT. For instance, Norton (1987) and Watson (1990) identifies that CBT increases motivation among learners.

It was also found from the study that CBT helps students to accept responsibility for their own learning outcomes and also help students to achieve competencies required for job performance. Since the Ghanaian labour market and industries now require graduates with competencies in technical and vocational skills and not just "classroom knowledge", it is deemed that CBT graduates with such competencies and skills stands an advantage in gaining employment to fit into jobs that require their competencies and skills.

It was also observed that in spite of the numerous benefits of CBT, the programme is saddled with challenges most especially in the mode of delivery and methods of assessment. Like many challenges facing educational institutions in Ghana, CBT is laden with huge financial challenges which adversely affect its effective delivery. This challenge has been the major bottleneck to the training of 
graduates with competent vocational and technical skills. Other major challenges are logistical and time challenges which mostly involved learning and training materials and facilities required for practical performances as well as the relatively short time required to complete or acquire a specific competency. This implies that without adequate funding and infrastructure, CBT will fail to live its vision of imparting practical hands on skills and competencies to polytechnic students. This can be attributed to the low patronage of CBT programmes at the polytechnics.

In conclusion, it can be logically deduced from the study that CBT will help graduates after their acquisition of competent skills and knowledge to create employable jobs that may have the potential to absorb many people who are unemployed. This implies that CBT helps trainees to acquire practical competencies needed for industrial development.

This can help to reduce the high graduate unemployment among many of the nation's youth. It also confirms many similar studies understating the benefits of CBT. The findings reveal that CBT has significant effects on the competencies and skills of polytechnic trainees which is very vital to the development of the nation by way of feeding local industries and the labour sector with required skills and competencies. Since the Ghanaian labour market and industries now require graduates with competent technical and vocational skills and not just "classroom knowledge", it is deemed that CBT graduates with such competencies and skills stands an advantage at being employed to fit into jobs that require their competencies and skills.

\section{Conclusion and Recommendation}

This study has provided insight into the challenges confronting CBT in the Polytechnics which makes it ineffective to achieve its objectives. Since CBT is more learner-centred that required more time, instructions using print, instructional technology and simulations, the absence of appropriate and modern learning and training facilities in many Polytechnics have the potential of adversely affecting the quality of delivery and assessment of CBT programmes.

The implication of the research findings presents a vital benchmark in exploring the contributions of CBT to a developing economy like Ghana. Besides this general implication, this study has several managerial and social policy implications that need to be addressed. It is therefore recommended that management and staff of Polytechnics package and advertise TVET to attract more junior and senior high school graduates and others to this form of educational training. This can be done by highlighting on the benefits derived from CBT in TVET.

In considering the findings and conclusion above, the researchers wish to recommend that a well-structured TVET policy should be formulated to encompass the recommendations outlined below:

(i) Adoption of best and appropriate teaching, training and learning approaches that are more learner-centred in addition to the use of instructional materials such as print instructional technology and other practical simulations during training sessions. This will make the programme attractive to learners and thereby increase enrolment.

(ii) The mode of assessing students should also be competency-based and not the traditional way of writing theoretical examinations. It should rather challenge the intellect and skills of trainers to prove their level of competence as this will be a sure way to achieve the desired objective of the CBT approach to education.

(iii) Additionally, governments should also support polytechnics financially and logistically since that would help train the middle and higher level manpower and skills needed by industry, commerce and trade to help make Ghana a highly industrialized nation.

(iv) Moreso, pragmatic policies regarding the placement of TVET graduates into the labour market, which will include positions and other remunerations should be developed. That is, appropriate scales of payment and ranks should be well established to encourage individuals who are skill-oriented to undertake the required training and not divert to other areas outside their interest.

(v) Also, governments should formulate policies such as tax reductions, waivers and other incentives that can help TVET graduates establish their own businesses. This will in the long run reduce unemployment in the country as well as help in GDP growth.

(vi) Another key recommendation is the proper identification of trainee skills in the training process. This will help in the appropriate placement of 
learners in the skill acquisition and development process. An individual will always perform best when working in an area that suits his/her interest as it will be done with much ease.

In relation to the conceptual framework developed above, it is evident that the expectations, perceived performance, expected output amidst the outlined limitations if effectively considered and managed, will bring in the desired result of the CBT concept

Above all, to ensure overall effectiveness of the CBT programme, all stakeholders spanning policy formulators, implementers and users of acquired skills; that is, employers, must collaborate at all levels of skills identification, development of curricular and teaching and training of learners. This will yield the results required to function appropriately in the workplace.

\section{References}

Afeti, G., Baffour-Awuah, D. and Budu-Smith J. (2003) Baseline Survey for the Introduction of Competency - Based Training in Polytechnics, National Council for Tertiary Education (NCTE)/ Japan Internal Cooperation Agency (JICA).

Amegashie-Viglo, S. (2005). Skill Training in the Informal Sector in the Volta Region: Problems, Challenges and Prospects. Journal of Polytechnics in Ghana, Vol. 1, 930

The Role of Technical and Vocational Education in the National Development of Bangladesh: Asia-Pacific Journal of Cooperative Education, 2008, 9(1), 25-44

Gyadu-Asiedu, W., Dzisi, S., Ms. Asirifi, P. K., and Boamaa, A. A. Assessing CompetencyBased Training (CBT) Approach to Polytechnic Education in Ghana. Paper presented at the CAPA Conference in Entebbe, Uganda. December 2014.

Boama, G. (2014), Assessing the Effects of Competency Based Training in the Polytechnics: A Study of Selected Polytechnics in Ghana. Thesis Submitted to University of Education, Winneba College of Technology Education

Chappell, C. (1996). "Quality \& Competency Based Education and Training. In the Literacy Education, pp. 71-79. Red Hill, Australia: Queensland Council for Adult Literacy
COTVET (2009) Competency-Based Training (CBT) in Ghana. Ghana. Report of the Technical Committee on the Harmonisation of CompetencyBased Training in Ghana.

Ecclestone, K. (1997). "Energising or Enervating?" Journal of Vocational Education and Training 49, No. 1, pp. 65-79

Foyster, J. (1990). Getting to Grips with Competency-Based Training and Assessment. TAFE National Centre for Research and Development: Leabrook, Australia. ERIC: ED 317849

Gondwe, M. \& Walenkamp, J. (2011). Alignment of Higher Education with the Needs of the Local Labour Market: The Case of Ghana. The Hague: Nuffic and The Hague University of Applied Sciences.

Harris, R., Guthrie, H., Hobart, B., and Lundberg, D. (1995). Competency Based Education and Training: Between a Rock and a Whirlpool. McMillan Education Australia: South Melbourne

Hendricson, W.D., and Kleffner, J.H. (1998). Curricular and Instructional Implications of Competency Based Dental Education, Journal of Dental Education, Vol. 62 pp. 183196

Hyland, T. (1994). Competence, Education and NVQs: Dissenting Perspectives. London Cassell

Lowrie, T., Smith, E. \& Hill, D. (1999) Competency based training: A staff development perspective. Adelaide: NCVER.

Norton, RE. (1987). Competency-Based Education and Training: A Humanistic and Realistic Approach to Technical and Vocational Instruction. Paper presented at the Regional Workshop on Technical/Vocational Teacher Training in Chiba City,Japan. ERIC: ED 279910

Nsiah-Gyabaah, K. (2007). The Change to Competency-Based Education in order to Match Labour Market Needs; Journal of Polytechnics in Ghana. Volume 2, No.2 pp. 1417

Nsiah-Gyabaah, K. (2009) The Missing Ingredients in Technical and Vocational Education in Meeting the Needs of Society and Promoting Socio-Economic Development in Ghana; Journal of Polytechnics in Ghana; Volume 3 No.3 pp. 6-11 
Delker, P. (1990). Delker PV. 1990. Basic Skills Education in Business and Industry: Factors for Success or Failure. Contractor Report, Office of Technology Assessment, United States Congress

Smith, E (1997). How competency-based training has changed teaching and learning. Training Agenda, Vol. 5 No. 4, pp.20-21

Thomas, A., Potter, D.. \& Allen, T. (1992). Development, capitalism and the nation state: Poverty and development in the 1990s. Milton, Keynes: Open University Press.

Thomson, P. (1991). Competency-Based Training: Some Development and Assessment Issues for Policy Makers. TAFE National Centre for Research and Development: Leabrook, Australia. ERIC: ED 333231
UNESCO-IBE (2011). World Data on Education VII Ed. 2010/11. Ghana. Geneva: UNESCO-IBE.

UNESCO-UNEVOC (2012). World TVET Database Ghana, UN Campus, Germany.

Watson, A. (1990). Competency-Based Vocational Education and Self-Paced Learning. Monograph Series, Technology University: Sydney, Australia. ERIC: ED 324443

Waymark, M. (1997) The impact of national vocational qualifications on the Secretarial Curriculum. Journal of Vocational Education and Training, 49(1), 107-120 